\title{
Investigation of antimicrobial use at a tertiary care hospital in Southern Punjab, Pakistan using WHO methodology
}

\author{
Muhammad Atif ${ }^{1 *}$, Muhammad Azeem ${ }^{1}$, Anum Saqib ${ }^{1}$ and Shane Scahill ${ }^{2}$
}

\begin{abstract}
Background: Globally, between 20 to $50 \%$ of antimicrobial consumption is inappropriate, causing significant impact on the quality of care, cost of therapy and incidence of adverse drug reactions. The purpose of this study was to investigate the prescribing patterns and utilization of antimicrobials in ten selected wards at Bahawal Victoria Hospital (BVH), Bahawalpur, Punjab, Pakistan.
\end{abstract}

Methods: A descriptive cross-sectional study was designed using the World Health Organization (WHO) indicators for antimicrobial use. Standard data collection forms were used in ten wards and the Pharmacy Department at BVH. Antimicrobial utilization patterns in terms of frequency and percentage were also determined. Systematic random sampling techniques were used to collect data from 1,000 prescription records out of 21,115 prescriptions written for the six months January to June 2016.

Results: For the hospital indicators, a formulary list or essential medicines list (FL/EML) was available, but standard treatment guidelines (STGS) for infectious diseases was not. The average number of days that key antimicrobials were out of stock was 3.3 days per month. The expenditure on antimicrobials as a percentage of the total medicines costs was $12.2 \%$. For the prescribing indicators, the percentage of hospitalizations with antimicrobial(s) prescribed was $82.3 \%$, and the average number of antimicrobials per hospitalization was $1.4(S D=0.6)$. The average duration of antimicrobial treatment per hospitalization was 5.4 days $(S D=3.2)$. The average cost of antimicrobials prescribed per hospitalization was USD $5.4(S D=6.7)$. None of the patients who were prescribed antimicrobials, received AM according to the STGs (pneumonia and cesarean section cases). Among the patient-care and supplemental indicators, the average duration of hospital stay of patients who received antimicrobials was 6.4 $(\mathrm{SD}=4.3)$ days. The drug sensitivity testing was almost non-existent, with only $0.24 \%$ prescription records having drug sensitivity tests. Ceftriaxone (39.6\%), metronidazole (23.4\%) and cefotaxime (23.1\%) were the top most frequently prescribed antimicrobials.

Conclusions: The results of the current study revealed less than optimal antimicrobial prescribing and utilization patterns of selected wards at BVH. Continuous education and training of physicians, and cost-effective policies could play an important role in promoting the rational use of antimicrobials in this setting.

Keywords: Irrational prescribing, WHO, Antimicrobial utilization, Rational, Antimicrobial use indicators, Antimicrobial resistance

\footnotetext{
* Correspondence: pharmacist_atif@yahoo.com

${ }^{1}$ Department of Pharmacy, The Islamia University of Bahawalpur, Bahawalpur,

Pakistan

Full list of author information is available at the end of the article
} 


\section{Background}

There is no doubt that antimicrobials have played a revolutionary role in healthcare systems worldwide [1]. From the discovery of the very first antibiotics in the 1930s and 1940s, these medicines have saved countless lives [1, 2]. This has been through reducing morbidity and mortality rates for number of infectious diseases that were once a principal cause of death $[3,4]$. However, the problem is not completely resolved as infectious diseases account for $20 \%$ of deaths globally; equating to 11 million deaths per annum [4]. This is largely due to the emergence of antimicrobial resistance (AMR), a phenomenon that was first observed in 1947, when microorganisms (Staphylococcus species) showed resistance against penicillin [5]. The rapidly emerging multi drug resistant (MDR) microbial species make the treatment options very limited, problematic, costly and with greater incidences of adverse drug reactions (ADRs) $[2,6]$.

A number of factors are thought to be associated with this rapidly developing AMR, but a large number of studies support the claim that inappropriate antimicrobial use (either prescribing antimicrobials when not required or prescribing a broad spectrum agent when a narrower spectrum agent would be adequate) $[7,8]$ is the main determinant of AMR [9-14]. One study has claimed that almost 30 to $50 \%$ of hospitalized patients receive at least one antimicrobial, and therefore, antimicrobials account for greater than $30 \%$ of total hospital budgets [15]. According to available literature, 20 to $50 \%$ of total antimicrobial consumption is inappropriate [13, 16, 17], causing significant impact on the quality of care [18], cost of therapy $[19,20]$ and incidence of ADRs [21].

Although, the problems associated with antimicrobials exist all over the world the developing countries are afflicted the most where infection rates are much higher and resources are very limited [22, 23]. For example, in Pakistan, due to limited resources, physicians working in government hospitals are forced to prescribe antimicrobials that have little or no effect against a number of microbes [24]. A number of studies from Pakistan have already reported high prescribing rates of antimicrobials as $51.5 \%$ [25], 52\% [26], 52.4\% [27], 48.9\% [28]. However, very limited data is available from Pakistan [29] about the antimicrobial prescribing patterns relating to the World Health Organization (WHO) antimicrobial use indicators [22]. Based on aforementioned reasons, it is important to implement a continuous antimicrobial consumption surveillance system using standard methodology in hospitals as part of AMR prevention strategies [30]. For this purpose, the WHO has developed a set of indicators to measure the prescribing and use of antimicrobials in hospitals [22]. These indicators are classified as hospital, prescribing, patient-care, and supplemental indicators.
The purpose of this study was to investigate the use and prescribing patterns of antimicrobials at 10 wards in the Bahawal Victoria Hospital (BVH), Bahawalpur, Punjab, Pakistan. The findings of the current study could be used to benchmark policy and practice activities regarding quality of antimicrobial use. Specifically, this insight will help policy-makers to implement appropriate interventions designed to improve the judicious use of antimicrobials in Pakistan and more globally.

\section{Methods \\ Study settings}

The study was conducted in the BVH, Bahawalpur, Punjab, Pakistan. The BVH is a tertiary level 1600-bed hospital with all specialties. Around 350 physicians, 20 pharmacists, 400 nurses and 3,000 paramedical staff attend an average of 90,000 patients per month [27]. Purposively, ten wards and the Pharmacy Department of the hospital were selected to collect the required data. Each of the wards had at least one pharmacist. The characteristics of the selected wards are summarized in Table 1.

\section{Study design and outcome variables}

It was a non-experimental and descriptive crosssectional study, designed according to the study objectives. The outcome indicators are related to four general areas of antimicrobial use; hospital, prescribing, patientcare and supplemental indicators. The antimicrobial use patterns in terms of frequency and percentage of single as well as multiple antimicrobials were also determined. The Anatomical Therapeutic Chemical (ATC) classification system was used for the coding of antimicrobials. The defined daily doses (DDDs) of antimicrobials were calculated and their comparison across wards was also determined [31].

Table 1 Characteristics of the selected wards at the Bahawal Victoria Hospital

\begin{tabular}{llllll}
\hline Sr. No. & Ward name & $\begin{array}{l}\text { No. of medical } \\
\text { doctors }\end{array}$ & $\begin{array}{l}\text { Paramedical } \\
\text { staff }^{\text {a }}\end{array}$ & $\begin{array}{l}\text { No of } \\
\text { beds }\end{array}$ & $\begin{array}{l}\text { Patient turn } \\
\text { over (monthly) }\end{array}$ \\
\hline 1 & $\begin{array}{l}\text { Chest } \\
\text { Disease Unit }\end{array}$ & 25 & 23 & 60 & 295 \\
2 & $\begin{array}{l}\text { Ear Nose } \\
\text { Throat }\end{array}$ & 16 & 15 & 42 & 176 \\
3 & Gynecology & 20 & 29 & 75 & 346 \\
4 & Medical 1 & 31 & 31 & 80 & 729 \\
5 & Medical 2 & 35 & 28 & 75 & 753 \\
6 & Nephrology & 7 & 10 & 40 & 63 \\
7 & Orthopedics & 40 & 32 & 88 & 500 \\
8 & Surgical 4 & 27 & 22 & 70 & 309 \\
9 & Skin & 21 & 12 & 20 & 48 \\
10 & Urology & 28 & 38 & 90 & 300 \\
\hline
\end{tabular}

${ }^{\text {a }}$ aramedical staff includes nurses, ward boys and sweepers working in the ward 


\section{Study inclusion/exclusion criteria}

The inclusion/exclusion criteria are provided in Additional file 1: Table S1.

\section{Sampling and data collection}

We used the standard indicator forms to collect data. Data reliability was ensured by following the WHO guidelines and methods [22, 32]. The data was collected during the months of June to July 2016.

\section{Hospital indicators}

The data regarding the hospital indicators were collected for a period of one year (i.e. July 2015 to June 2016), except for indicator 4 (the average number of days that a set of key antimicrobials is out of stock), that was determined based on the data collected for a duration of six months (i.e. January to June 2016). The most recent copies of the Formulary List or Essential Medicines List (FL/EML), key antimicrobials and standard treatment guidelines (STGs) were obtained from the Pharmacy Department. The WHO hospital indicators, their data sources and the standard data collection forms are in Additional file 1: Table S2.

\section{Prescribing, patient-care and supplemental indicators, and prescribing patterns of antimicrobials}

One thousand prescription records (100 per ward) out of a total of 21,115 prescriptions written from January to June 2016 were selected. To minimize selection bias prescription records written for each ward were divided into four parts, and from each part 25 prescriptions were selected using a systematic random sampling technique [33]. The sampling unit was the prescriptions records written for inpatients only. From these prescription records, prescribing indicators, patient-care indicators, supplemental indicator, and prescribing patterns of antimicrobials were determined. The WHO prescribing, patient-care and supplemental indicators, their data sources and standard data collection forms are summarized in Additional file 1: Table S3.

\section{Data analysis}

Statistical Package for Social Sciences (IBM Corp. Released 2012. IBM SPSS Statistics for Windows, Version 21.0. Armonk, NY: IBM Corp.) and Microsoft Excel (MS Office 2010) were used for data analysis. Descriptive statistics were used to present the results. Difference in performance among various wards was established using the ANOVA test. Statistical significance was determined at $p<0.05$. Conversion rate of United States Dollars $(\mathrm{USD})$ to Pakistan Rupees (PKR) was $1 \mathrm{USD}=104.81 \mathrm{PKR}$.

\section{Results}

Demographic characteristics

From the 1,000 prescription records, $44.6 \%$ patients were male and $55.4 \%$ were female. The demographic characteristics of the patients included in the current study are summarized in Table 2.

\section{Hospital indicators}

The Drug and Therapeutic Committee (DTC) functions in an ongoing basis in the $\mathrm{BVH}$, and the hospital had a FL/EML that contains 25 generic antimicrobials. The results of the hospital indicators are summarized in Table 3.

Twenty five antimicrobials listed in FL/EML were available across 32 different dosage forms. Out of these 32 dosage forms, 30 (93.8\%) were available (in stock) on the study day (Additional file 1: Table S4). The average number of days that a set of key antimicrobials was out of stock was 3.3 days per month (Additional file 1: Table S5).

In the $\mathrm{BVH}$, for the year 2015-2016 approximately USD 6.58 million was allocated for the purchase of medicines. The expenditure on antimicrobials as a percentage of the total spend was $12.2 \%$ (USD 0.8 million). The proportion costs of individual antimicrobial was also calculated (Additional file 1: Table S6).

\section{Prescribing indicators}

The percentage of hospitalizations with antimicrobial(s) prescribed was $82.3 \%$, and from these patients, the average number of antimicrobials per hospitalization was 1.4 $(\mathrm{SD}=0.6)$. The results regarding prescribing indicators in the selected wards are summarized in Table 4.

From a total of 100 cesarean section cases, none received surgical antimicrobial prophylaxis in accordance with the clinical guidelines (Table 5).

Table 2 Demographic characteristics of the patients

\begin{tabular}{lll}
\hline Patient Variables & & Results \\
& & $n(\%)$ \\
\hline Gender & Male & $446(44.6)$ \\
& Female & $554(55.4)$ \\
Age (years) & $18-35$ & $276(27.6)$ \\
& $36-55$ & $199(19.9)$ \\
& $>55$ & $525(52.5)$ \\
Residence & Rural & $740(74)$ \\
Income ${ }^{a}$ (Pakistani Rupees per annum) & Urban & $260(26)$ \\
& $<300,000$ & $656(65.6)$ \\
& $300,000-1000,000$ & $338(33.8)$ \\
Comorbidity & $>1000,000$ & $6(0.6)$ \\
& Present & $554(55.4)$ \\
& Absent & $454(45.4)$ \\
\hline
\end{tabular}

${ }^{\mathrm{a}} 1 \mathrm{USD}=104.81 \mathrm{PKR}$ 
Table 3 WHO hospital indicators

\begin{tabular}{lll}
\hline Sr. No. & Parameter & Results \\
\hline 1 & Existence of DTC & Yes \\
2 & Existence of STGs for infectious diseases & No \\
3 & $\begin{array}{l}\text { Existence of FL/EML } \\
4\end{array}$ & Yes \\
& $\begin{array}{l}\text { Total number of antimicrobials on } \\
\text { the FL/EML }\end{array}$ & 25 generics \\
5 & Are all medicines identified by INN & Yes \\
6 & $\begin{array}{l}\text { Availability of a set of key antimicrobials } \\
\text { in the hospital stores on the day of study }\end{array}$ & $93.8 \%$ \\
7 & $\begin{array}{l}\text { Average number of days that a set of } \\
\text { key antimicrobials is out of stock }\end{array}$ & 3.3 days $/$ month \\
8 & $\begin{array}{l}\text { Total number of hospital discharges } \\
\text { during the last calendar year }\end{array}$ & 128,940 \\
9 & $\begin{array}{l}\text { Surgical interventions performed during } \\
\text { the last calendar year }\end{array}$ & Major $=28,257$ \\
& $\begin{array}{l}\text { Expenditure on antimicrobials as a } \\
\text { percentage of the total hospital medicine } \\
\text { costs }\end{array}$ & Minor $=17,739$ \\
&
\end{tabular}

DTC Drug and therapeutic committee, STGs Standard treatment guidelines, FL/ $E M L$ Formulary list/essential medicines list, INN International non-proprietary names

${ }^{a}$ Annual bulk purchase data only

\section{Patient-care and supplemental indicators}

The results regarding prescribing indicators are summarized in Table 6.

Antimicrobial utilization was determined based on the WHO's DDDs recommendations [31]. The total antimicrobial consumption in the selected wards varied between 2.32 DDD/1000 hospitalization days and 322.66 $\mathrm{DDD} / 1000$ hospitalization days. It is worth noting that $1.2 \mathrm{~g}$ amoxiclav had the highest consumption, in the range $0.5 \mathrm{DDD} / 1000$ hospitalization days to $209 \mathrm{DDD} /$ 1000 hospitalization days (Table 7).

\section{Prescribing patterns of antimicrobials}

Out of $823(82.3 \%)$ prescriptions with antimicrobial(s) prescribed, $536(65.13 \%)$ had one antimicrobial, 252 (30.62\%) included two antimicrobials and 34 (4.13\%) had three antimicrobials. Ceftriaxone (39.61\%), metronidazole $(23.45 \%)$ and cefotaxime $(23.09 \%)$ were the most frequently prescribed antimicrobials in the selected wards (Table 8). Ceftriaxone was the most commonly prescribed antimicrobial in the Chest Disease Unit (CDU), Medical 1, Medical 2, Orthopedics and Surgical 4 wards (Additional file 1: Table S7).

The patients admitted to the selected wards of the BVH were also prescribed antimicrobial combinations. The most frequently prescribed combinations were cefotaxime with metronidazole (11.5\%) and ceftriaxone with metronidazole (4.4\%) (Table 9$)$.

\section{Discussion}

Though problems associated with the "less than optimal" use of antimicrobials exist all over the world, the gravity of the problem is higher in the developing countries where infection rates are high but resources are very limited [22, 23]. In this study, the practices associated with antimicrobial use have been investigated at ten wards selected within a tertiary care hospital which may help the policy makers for process improvement.

\section{Hospital indicators}

The presence of FL/EML and STGs in a healthcare facility represents its commitment to provide good quality patient-care and promote rational use of medicines [22]. The BVH has a formulary list containing 25 generics of antimicrobials, approved by the hospital administration and it is revised on annual basis. There are however no STGs for infectious diseases (Table 3). In the absence of STGs for infectious diseases, prescribers do not have a standard to follow and they can prescribe antimicrobials freely, making it difficult to measure whether antimicrobial prescribing is rational or not. This may lead to an adverse impact on equitable access to essential drugs, thus compromising the quality of patient-care [22].

Besides the availability of STGs, it is essential that the key antimicrobials should be available all the time at hospitals. At the BVH, 93.8\% of a set of key antimicrobials were available on the day of the study (Additional file 1: Table S4). This value is comparable with a study from Ethiopia that reported the availability of key antimicrobials in stock as $90.1 \%$ [34]. The average number of days that a set of key antimicrobials is out of stock indicates the capacity a healthcare facility has for maintaining stock and determines the procurement and proper distribution procedures. The resulting value for indicator 4 was 3.3 days per month for the 32 key antimicrobials (Additional file 1: Table S5). This value was lower than those reported by studies conducted in Afghanistan (8.7 days per month for 15 key antimicrobials) [35] and Ethiopia (15-45 days over a 12-months period) [34]. The unavailability of key antimicrobials may force prescribers to prescribe medicines outside the FL/EML. Patients may not be able to get the drug of choice for particular infectious diseases, or they may be forced to buy branded or expensive medicines, or they might not receive any treatment at all. This may lead to economic burden on patients and non-compliance issues, as well as increased risk of morbidity and mortality [22].

Due to excessive and improper use of antimicrobials, the cost imposed by this single class of drugs is rising. Indicator 5 records the cost of antimicrobials and demonstrates it as percentage of total hospital medicines costs. Results of the current study showed that the annual budget allocated for all medicines was USD 6.58 


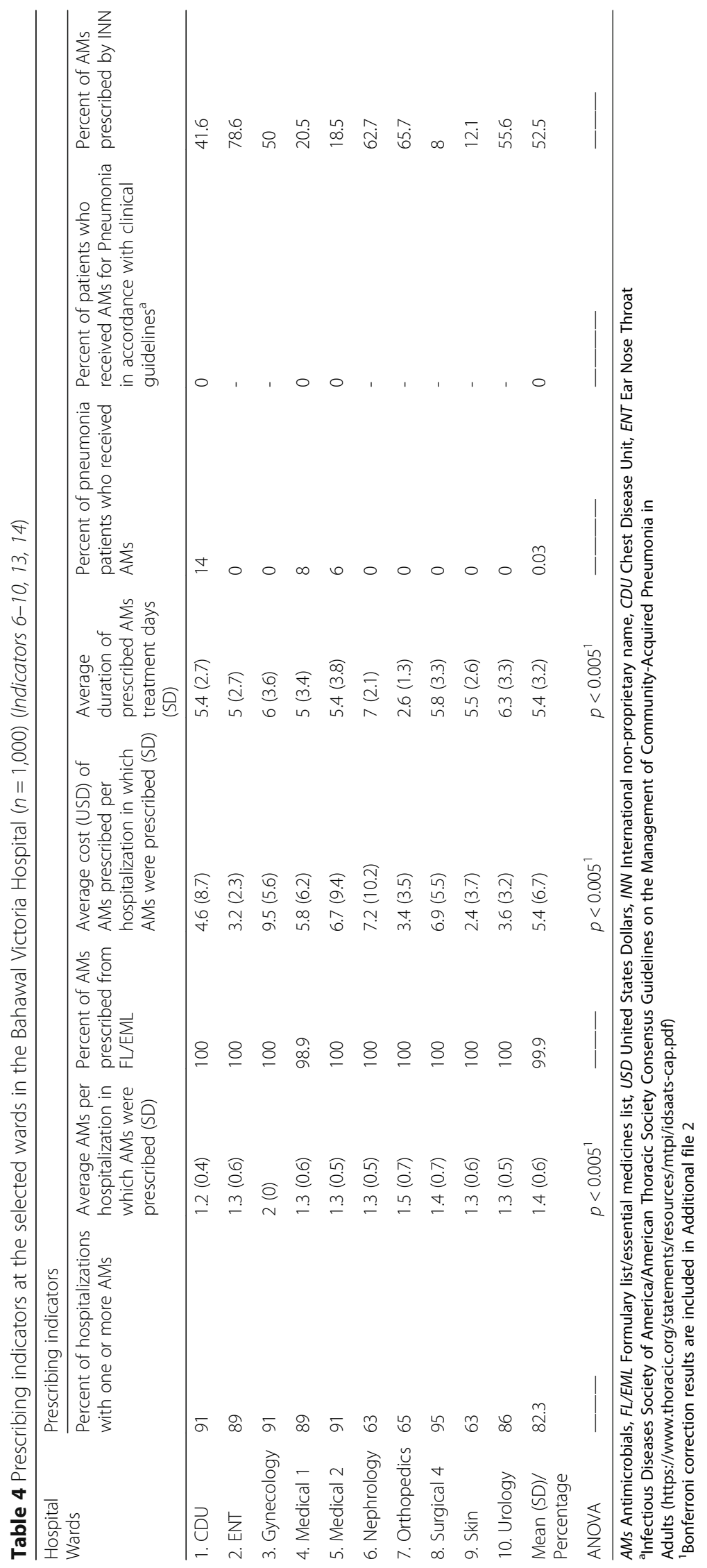


Table 5 Surgical antimicrobial prophylaxis indicators (Indicators 11, 12)

\begin{tabular}{lll}
\hline Sr. No. & Parameters & Results \\
\hline 1 & $\begin{array}{l}\text { Number of cesarean section cases } \\
2\end{array}$ & $\begin{array}{l}\text { Surgical antimicrobial prophylaxis prescribed } \\
\text { for patients }\end{array}$ \\
3 & $\begin{array}{l}\text { Total number of doses of surgical antimicrobial } \\
\text { prophylaxis prescribed for cesarean section } \\
\text { procedures }\end{array}$ & 65 \\
& $\begin{array}{l}\text { Average number of doses of surgical antimicrobial } \\
\text { prophylaxis prescribed for cesarean section } \\
\text { procedures }\end{array}$ & $1.2 \pm 0.4$ \\
& $\begin{array}{l}\text { Percentage of patients who received surgical } \\
\text { antimicrobial prophylaxis for cesarean section } \\
\text { in accordance with clinical guidelines }\end{array}$ & 0 \\
\hline
\end{tabular}

${ }^{a}$ Clinical Practice Guidelines for Antimicrobial Prophylaxis in Surgery (www.ashp.org/surgical-guidelines)

million of which the expenditure on antimicrobials (annual bulk purchase data only) was 12.2\% (Additional file 1: Table S6). The reason for this low percentage was that the data from multiple and local purchase orders were not readily available and the data presented here is from a one-time annual purchase record.

\section{Prescribing indicators}

Indicator 6 determines the extent of antimicrobial prescribing in a healthcare facility. In our study, the percentage of hospitalizations with antimicrobial(s) prescribed was $82.3 \%$ (Table 4 ). This value was lower than that reported by studies from Afghanistan (90\%) [35] and Nepal (93\%) [36], and higher than Ethiopia (79.8\%) [34], Thailand (44\%) [37], Bangladesh (25\%) [38], Tanzania (35.4\%) [39] and Brazil (28.8\%) [40]. During hospitalization, patients may be prescribed more than one antimicrobial. This prescribing may be appropriate according to the condition of patients, but it may also be a result of prescribing which is not optimal such as duplication of medicines, inappropriate use of combination therapy, and/or frequent and unnecessary alterations in dosage regimens [22]. In this study, the average number of antimicrobials per hospitalization (indicator 7) was 1.4 ( $\mathrm{SD}=0.6)$, and the difference among wards was found to be statistically significant $(p<0.005)$ (Table 4$)$. A study from Ethiopia reported a lower value (1.2) [34], while studies conducted in Afghanistan (1.7) [35] and Nepal (2.4) [36] reported somewhat higher values. The study findings regarding antimicrobial prescribing showed that antimicrobials were prescribed to the majority of patients admitted to various wards of the $\mathrm{BVH}$, but the number of antimicrobials being prescribed was not huge [22]. Indicator 10 determines the length of time antimicrobials are prescribed and the extent of antimicrobial exposure to patients while they are hospitalized. The usual duration of treatment with antimicrobials for most of the infectious diseases is $7-10$ days, but some diseases may also require longer durations such as osteomyelitis and meningitis [22]. In the $\mathrm{BVH}$, the average duration of prescribed antimicrobial treatment was 5.4 days $(\mathrm{SD}=3.2)$, and the difference among wards was found to be statistically significant $(p<0.005)$ (Table 4). A study from Afghanistan also reported comparable results of 5 days [35].

The WHO strongly recommends prescribing of medicines by their INN or generic names. Indicator 14 measures the percentage of antimicrobials prescribed

Table 6 Patient-care and supplemental indicators at the selected wards in the Bahawal Victoria Hospital (Indicators 15-17)

\begin{tabular}{|c|c|c|c|c|}
\hline \multirow[t]{2}{*}{ Hospital Wards } & \multicolumn{4}{|c|}{ Patient-care and supplemental indicators } \\
\hline & $\begin{array}{l}\text { Number of AM doses } \\
\text { prescribed Sum } \\
(\text { mean } \pm \text { SD) }\end{array}$ & $\begin{array}{l}\text { Percent of doses of } \\
\text { prescribed AM actually } \\
\text { administered }\end{array}$ & $\begin{array}{l}\text { Average duration of hospital stay } \\
\text { of patients who received AM (SD) }\end{array}$ & $\begin{array}{l}\text { Number of AM drug sensitivity } \\
\text { tests reported per hospital } \\
\text { admission with curative AM } \\
\text { prescribed }\end{array}$ \\
\hline 1. CDU & $1134(12.5 \pm 7.7)$ & 100 & $5.8(3.2)$ & 1 \\
\hline 2. ENT & $1116(12.5 \pm 7.8)$ & 100 & $5.1(2.8)$ & 0 \\
\hline 3. Gynecology & $2635(29 \pm 17.1)$ & 100 & $6.3(4.1)$ & 0 \\
\hline 4. Medical 1 & $1188(13.4 \pm 11.4)$ & 100 & $5.9(3.9)$ & 1 \\
\hline 5. Medical 2 & $1231(13.5 \pm 10.2)$ & 100 & $5.9(3.9)$ & 0 \\
\hline 6. Nephrology & $1282(20.4 \pm 11.9)$ & 100 & $8.2(2.8)$ & 0 \\
\hline 7. Orthopedics & $452(7 \pm 5.3)$ & 100 & $3.5(2.5)$ & 0 \\
\hline 8. Surgical 4 & $1663(17.5 \pm 11.3)$ & 100 & $7.3(5.8)$ & 0 \\
\hline 9. Skin & $1049(16.6 \pm 8.2)$ & 100 & $7.5(5.3)$ & 0 \\
\hline 10. Urology & $1297(15.1 \pm 9.3)$ & 100 & $8.2(5.1)$ & 0 \\
\hline Mean (SD)/ Percentage & $13047(15.9 \pm 12)$ & 100 & $6.4(4.3)$ & $0.002 \%$ \\
\hline ANOVA & $p<0.005^{*}$ & - - & $p<0.005$ & - - \\
\hline
\end{tabular}




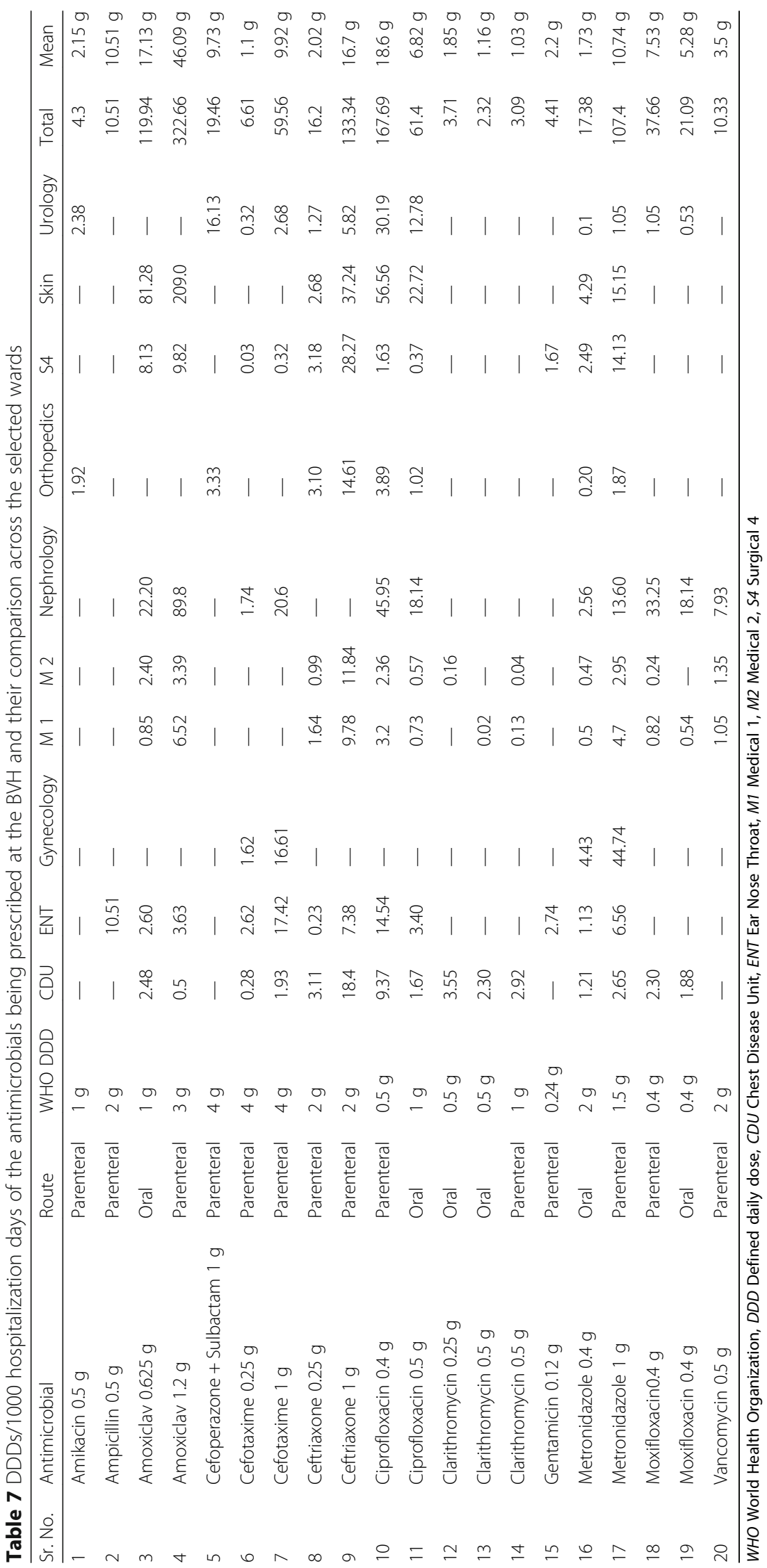


Table 8 Frequency of various antimicrobials being prescribed at the selected wards of the Bahawal Victoria Hospital $(n=823)$

\begin{tabular}{lllll}
\hline Sr. No. & Antimicrobial name & ATC Code & No. of hospitalizations & Percentage \\
\hline 1 & Ceftriaxone & J01DD04 & 326 & 39.6 \\
2 & Metronidazole & J01XD01 & 193 & 23.4 \\
3 & Cefotaxime & J01DD01 & 190 & 19.1 \\
4 & Amoxiclav & J01CR02 & 162 & 13.7 \\
5 & Ciprofloxacin & J01MA02 & 110 & 7.5 \\
6 & Cefoperazone & J01DD12 & 62 & 2.7 \\
7 & Clarithromycin & J01FA09 & 22 & 2.4 \\
8 & Moxifloxacin & J01MA14 & 20 & 1.9 \\
10 & Cephradine & J01DB09 & 16 & 1.5 \\
11 & Vancomycin & J01XA01 & 12 & 1.3 \\
12 & Ampicillin & J01CA01 & 11 & 1.3 \\
\hline
\end{tabular}

ATC Anatomical therapeutic chemical classification system

by their INN or generic names which was $52.5 \%$ at BVH (Table 4). This value was much lower compared to studies conducted in Afghanistan (88\%) [35] and Thailand (87\%) [37]. Antimicrobials prescribed by brand names may increase the chance of medication errors, thus prolonging morbidity and mortality along with putting extra financial pressure on individual the patients and healthcare budgets as a whole [41].

Since antimicrobials account for greater than $30 \%$ of total hospital budgets [15], this poses huge financial implications when they are not appropriately prescribed. Indicator 9 measures the average cost of antimicrobials prescribed to hospitalized patients [22]. The findings of the current study demonstrated that the average cost of antimicrobials prescribed per hospitalization was USD 5.4 $(\mathrm{SD}=6.7)$, and the difference among wards was found to be statistically significant $(p<0.005)$ (Table 4$)$. In case of public sector hospitals in Pakistan, the government is the only financing agency which has to bear the healthcare costs. Unfortunately, there are no compulsory health insurance schemes in Pakistan. Therefore, USD 5.4 per patient on this single class of drugs (antimicrobials) may pose a huge financial burden on the government as well as on patients belonging to the lower

Table 9 Most commonly prescribed antimicrobial combinations at the selected wards of the Bahawal Victoria Hospital

\begin{tabular}{lll}
\hline Sr. No. & Antimicrobial combination & Frequency (\%) \\
\hline 1 & Cefotaxime + Metronidazole & $95(11.5)$ \\
2 & Ceftriaxone + Metronidazole & $36(4.4)$ \\
3 & Ciprofloxacin + Metronidazole & $18(2.2)$ \\
4 & Amoxiclav + Metronidazole & $14(1.7)$ \\
5 & Ciprofloxacin + Cefoperazone/Sulbactam & $11(1.3)$ \\
6 & Ceftriaxone + Clarithromycin & $10(1.2)$ \\
\hline
\end{tabular}

income class. This may also be a reason for the unavailability and "stock out" of essential medicines and antimicrobials in the public sector hospitals, which has also been reported in our study. Similar to our findings, the cost of antimicrobials prescribed per hospitalization was USD 6.7 in Nigeria [42] whereas it was much lower in India at only USD 1.3 [43].

In cases of cesarean section surgical procedures, antimicrobial prophylaxis is recommended to avoid infections and the recommended regimen is the administration of one dose within one hour of the surgical procedure [44]. Indicators 11 and 12 focus on the patients receiving surgical antimicrobial prophylaxis for cesarean section procedures. The assessment is whether they receive the prophylactic antimicrobial treatment in accordance with the clinical guidelines or not, and how many doses they receive [22]. The findings of this study showed that out of 100 cesarean section cases, 54 patients were prescribed surgical antimicrobial prophylaxis and none of these received this in accordance with the STGs. The average number of doses of surgical antimicrobial prophylaxis prescribed for cesarean section procedures was $1.2(\mathrm{SD}=0.4)$ (Table 5). Since the hospital did not have its own STGs for surgical antimicrobial prophylaxis, previously published guidelines [45] were used as a reference.

It is necessary to follow the STGs for proper treatment of pneumonia or any other infection requiring antibiotics [35]. If STGs are unavailable or not followed adequately, there is a high probability that prescribing will be less than optimal and that utilization of antimicrobials will be excessive. This is likely to lead to increased incidences of ADRs, hospitalizations, and financial burden. The adherence of prescribers to the hospital's STGs depends on two factors; prescribing only those antimicrobials listed in STGs; and prescribing within the 
dosage guidelines outlined in the STGs [22]. Indicator 13 measures the percentage of pneumonia patients who receive antimicrobials in accordance with the appropriate STG. The results of the current study show that of the 28 reported cases of pneumonia none received antimicrobials in accordance with the clinical guidelines (Table 4). The hospital did not have STGs for pneumonia, therefore, previously published guidelines [46] were used as a reference. A study from Afghanistan also reported similar results that none of the patients received treatment in accordance with treatment guidelines [35].

\section{Patient-care and supplemental indicators}

The frequency of performing antimicrobial sensitivity tests (indicator 17) is significant in determining the level of prescriber's adherence to the STGs and the hospital's ability to deliver appropriate antimicrobial treatment. The results of the current study reveal that drug sensitivity testing was almost non-existent; only 2 (0.24\%) prescription records had a report of drug sensitivity tests (Table 6). This value is comparable with the studies from China (0.5\%) [47] and Afghanistan (0.0\%) [35]. Studies from Nigeria (20.53\%) [48] and Nepal (19.8\%) [36] reported higher levels of culture sensitivity testing.

The rational use of antimicrobials demands that patients should not be retained in hospitals longer than what is recommended in the STGs, and that they should also receive all prescribed doses of antimicrobials. Indicator 15 determines the duration of stay at hospital for inpatients as an index of treatment effectiveness. The results of the current study reveal that the average duration of hospital stay of patients was 6.4 $(\mathrm{SD}=4.3)$ days, and the difference among the wards was found to be statistically significant $(p<0.005)$ (Table 6). In most of the infectious disease cases, this duration of stay is acceptable. The results of the current study regarding indicator 16 showed that all the prescribed doses of antimicrobials were administered to the hospitalized patients (Table 6), which is a good indication of rational use of antimicrobials; at least from the viewpoint of medicines adherence.

In-order to promote the rational use of medicines it is mandatory to follow the WHO's recommendations regarding defined daily doses of medicines (DDD). There were only three antimicrobials $(0.25 \mathrm{~g}$ ceftriaxone, $0.5 \mathrm{~g}$ clarithromycin and $0.4 \mathrm{~g}$ metronidazole) for which the mean observed doses were identical to the WHO recommended DDDs. Some drugs were given in lower DDDs than those recommended, such as 0.25 g cefotaxime. On the contrary, other antimicrobials were usually administered at a dosage that exceeded the WHO-recommended DDDs. The most extreme example of this was ciprofloxacin $0.4 \mathrm{~g}$. WHO-recommended DDDs for $0.4 \mathrm{~g}$ ciprofloxacin was $0.5 \mathrm{~g}$; whereas, the mean administered DDD was more than 37 fold i.e., $18.6 \mathrm{~g}$ (Table 7). This is of significant concern and warrants intervention at the levels of hospital policy and individual prescriber.

\section{Prescribing patterns of antimicrobials}

There is a literature indicating that the consumption of antimicrobial is higher in developing than developed countries [49]. A study reported that 35 to $60 \%$ of patients were prescribed antimicrobials and less than $20 \%$ were prescribed appropriately [50]. In this study, out of $823(82.3 \%)$ prescriptions with antimicrobial(s) prescribed, $536(65.1 \%)$ had one antimicrobial, 252 (30.6\%) included two and $34(4.1 \%)$ had three antimicrobials. These findings could be compared with a Jordanian study [51], which indicated that out of $85 \%$ prescriptions with antimicrobials, $88 \%$ prescriptions had one, $11 \%$ had two and $1 \%$ had three antimicrobials. According to our findings, ceftriaxone (39.6\%), metronidazole $(23.4 \%)$ and cefotaxime $(23.1 \%)$ were the most commonly prescribed antimicrobials (Table 8). The possible reasons behind high prescribing rates of these antimicrobials may include better clinical outcomes and excessive stock, or this might be the result of excessive and effective marketing strategies of pharmaceutical companies. A study performed in Ethiopia revealed that the most frequently prescribed antimicrobials were penicillin G (28.4\%), ceftriaxone (24.9\%) and cloxacillin (12.84\%) [34]. An Indian study revealed that the most commonly prescribed antimicrobials were levofloxacin (25.77\%), metronidazole (14.77\%) and ceftriaxone $(12.71 \%)$. Generally, the majority of infectious cases are treated for period less than two weeks, but severe and complicated cases may demand multiple antimicrobials for prolonged durations [52-54]. These multiple antimicrobial treatments are usually expected to provide broad antimicrobial cover [55]. The results of the current study reveal that the most frequently prescribed antimicrobial combinations were cefotaxime with metronidazole (11.5\%) and ceftriaxone with metronidazole (4.4\%) (Table 9). Indications for using these antimicrobial combinations include synergism, empirical therapy for poly-microbial infections and prevention of AMR development [56]. Usually, synergistic effects of antimicrobial combinations are desired when there are high risks of therapeutic failure with individual antimicrobials or greater probability of developing resistant strains $[57,58]$. Recent studies rebut this argument through reporting synergistic combinations that may enhance the development of resistant strains [59-61]. Other associated risks with the use of antimicrobial combinations include development of super infections, greater toxicity and increased financial burden [56].

There are several limitations to this study. First, as antimicrobial use was investigated in one hospital the findings of this study cannot be generalized for the whole of Pakistan. However, it is a fact that uniform healthcare 
policies are implemented in all the hospitals by the Pakistani government. As such clinical practices are assumed to be consistent with practices in other tertiary care hospitals in Pakistan. Second, different wards in the tertiary-care hospital have varying degrees of antimicrobial use. As such, to address this bias mean values for each of the selected wards were calculated separately. The reasons behind prescribing practices and particularly those factors that lead to less than optimal use of antimicrobials were not explored. Further studies should focus on these issues.

\section{Conclusions}

This was a drug utilization study using WHO methodology, conducted to explore the antimicrobial utilization in ten selected wards of the BVH, Bahawalpur, Pakistan. The results of the current study highlight that antimicrobial prescribing and utilization patterns are less than optimal. This is in terms of STG availability and compliance, antimicrobial stock out days, percentage of antimicrobial prescribing and prescribing of antimicrobials by INN, average cost per patient, and antimicrobial sensitivity testing; where things could be improved.

There are significant implications of this present study for policy and practice. Pakistan is a nation with a developing health care system and pharmaceutical policy is in its infancy. This study provides the impetus to bring into line prescribing practices in $\mathrm{BVH}$ and to set higher level policy via the DTC and implement training that ensures the optimal use of antimicrobials. Based on the study findings, it is recommended that DTC should develop and implement STGs for infectious diseases at the BVH. Patient-specific microbiological diagnosis of infectious diseases is also recommended. Infectious diseases specialist pharmacists should be appointed as they can play critical role in process improvement by developing and implementing a surveillance system in the hospital. They can search and provide data about the most common strains of microbes in Bahawalpur; and provide the necessary training to prescribing staff on a continuous basis. Policy makers should develop interventions that aim to minimize the costs associated with antimicrobial use. Studies based on these indicators should be conducted in all developing countries to obtain baseline and uniform data that will help in establishing international collaborations for the development of targeted interventions to promote the rational use of antimicrobials and the containment of AMR.

\section{Additional files}

Additional file 1: Table S1. Study inclusion/exclusion criteria. Table S2. WHO hospital indicators. Table S3. WHO prescribing, patient-care and supplemental indicators. Table S4. Availability of a set of key antimicrobials in the hospital stores on the day of study (Indicator No. 3). Table S5.

Average number of days that a set of key antimicrobials is out of stock
(Indicator No. 4). Table S6. Percentage of individual antimicrobial costs based on the total cost of antimicrobials (Indicator No. 5). Table S7. Prescribing patterns of single antimicrobials at the selected wards of the Bahawal Victoria Hospital. (DOCX 34 kb)

Additional file 2: Bonferroni correction. (DOCX 26 kb)

\section{Abbreviations}

ADRs: Adverse drug reactions; AM: Antimicrobial; AMR: Antimicrobial resistance; ANOVA: Analysis of variance; API: Active pharmaceutical ingredient; ATC: Anatomical therapeutic chemical; BVH: Bahawal Victoria Hospital; CDU: Chest disease unit; $\mathrm{CH}$ : Clinical history; DTC: Drug and therapeutic committee; ENT: Ear, Nose, Throat; FL/EML: Formulary list/Essential medicines list; INN: International nonproprietary names; MDR: Multiple drug resistance; PKR: Pakistani Rupee; STGs: Standard treatment guidelines; USD: United States Dollar; WHO: World Health Organization

\section{Acknowledgements}

The authors would like to thank the record officers at BVH for their help in data retrieving.

\section{Funding}

No funding was involved in the preparation of this article or in the decision to submit it for publication.

\section{Availability of data and materials}

The raw data on which conclusions of this manuscript rely is available upon request. Please contact Muhammad Azeem at azeem634@hotmail.com.

\section{Authors' contributions}

MAT made substantial contribution to conception and design of the study. MAZ, AS and SS also made contributions to the conception and design of the article. MAZ was involved in data collection and interpretation. MAT and MAZ drafted the manuscript. AS drafted the revised manuscript. SS critically revised the manuscript. Final version of the manuscript was approved by all authors, and all authors are accountable to the accuracy and integrity of all parts of the paper.

\section{Competing interests}

The authors declare that they have no competing interests.

Consent for publication

Not applicable.

\section{Ethics approval and consent to participate}

The ethical approval was obtained from the Pharmacy Research Ethics Committee (PREC) at the Islamia University of Bahawalpur (Reference: 22-2015/ PREC, dated February 02, 2015). The permission to conduct this study was also obtained from the Medical Superintendent of the BVH.

\section{Publisher's Note}

Springer Nature remains neutral with regard to jurisdictional claims in published maps and institutional affiliations.

\section{Author details}

'Department of Pharmacy, The Islamia University of Bahawalpur, Bahawalpur, Pakistan. ${ }^{2}$ School of Management, Massey University, Auckland, New Zealand.

Received: 30 December 2016 Accepted: 21 April 2017

Published online: 28 April 2017

\section{References}

1. Cantas L, Shah SQ, Cavaco LM, Manaia CM, Walsh F, Popowska M, et al. A brief multi-disciplinary review on antimicrobial resistance in medicine and its linkage to the global environmental microbiota. Front Microbiol. 2013;4: 96. doi:10.3389/fmicb.2013.00096.

2. Davies J, Davies D. Origins and evolution of antibiotic resistance. Microbiol Mol Biol Rev. 2010;74(3):417-33. doi:10.1128/MMBR.00016-10. 
3. Laxminarayan R, Duse A, Wattal C, Zaidi AK, Wertheim HF, Sumpradit N, et al. Antibiotic resistance-the need for global solutions. Lancet Infect Dis. 2013;13(12):1057-98. doi:10.1016/S1473-3099(13)70318-9.

4. Pollack LA, Srinivasan A. Core elements of hospital antibiotic stewardship programs from the Centers for Disease Control and Prevention. Clin Infect Dis. 2014;59 Suppl 3:S97-100. doi:10.1093/cid/ciu542.

5. Barber M, Rozwadowska-Dowzenko M. Infection by penicillin-resistant staphylococci. Lancet. 1948;2(6530):641-4.

6. Ventola CL. The antibiotic resistance crisis: part 1: causes and threats. P T. 2015:40(4):277-83.

7. Dellit TH, Owens RC, McGowan Jr JE, Gerding DN, Weinstein RA, Burke JP, et al. Infectious Diseases Society of America and the Society for Healthcare Epidemiology of America guidelines for developing an institutional program to enhance antimicrobial stewardship. Clin Infect Dis. 2007;44(2): 159-77. doi:10.1086/510393.

8. Gums JG, Yancey Jr RW, Hamilton CA, Kubilis PS. A randomized, prospective study measuring outcomes after antibiotic therapy intervention by a multidisciplinary consult team. Pharmacotherapy. 1999;19(12):1369-77.

9. Levy SB, Marshall B. Antibacterial resistance worldwide: causes, challenges and responses. Nat Med. 2004;10 Suppl 12:S122-129. doi:10.1038/nm1145.

10. English BK, Gaur AH: The use and abuse of antibiotics and the development of antibiotic resistance. In: Hot Topics in Infection and Immunity in Children VI. edn. New York: Springer International Publishing AG; 2010: p. 73-82.

11. Okeke IN, Klugman KP, Bhutta ZA, Duse AG, Jenkins P, O'Brien TF, et al. Antimicrobial resistance in developing countries. Part II: strategies for containment. Lancet Infect Dis. 2005;5(9):568-80. doi:10.1016/S1473-3099(05)70217-6.

12. Austin DJ, Kristinsson KG, Anderson RM. The relationship between the volume of antimicrobial consumption in human communities and the frequency of resistance. Proc Natl Acad Sci U S A. 1999;96(3):1152-6.

13. Čižman $M$. The use and resistance to antibiotics in the community. Int J Antimicrob Agents. 2003;21(4):297-307.

14. Swartz MN. Use of antimicrobial agents and drug resistance. N Eng J Med. 1997;337(7):491-2.

15. Vlahovic-Palcevski V, Morovic M, Palcevski G. Antibiotic utilization at the university hospital after introducing an antibiotic policy. Eur J Clin Pharmacol. 2000;56(1):97-101.

16. Mora $Y$, Avila-Agüero ML, Umaña MA, Jiménez AL, París MM, Faingezicht I. Epidemiologic observations of the judicious use of antibiotics in a pediatric teaching hospital. Int J Infect Dis. 2002;6(1):74-7.

17. Gottlieb T, Nimmo GR. Antibiotic resistance is an emerging threat to public health: an urgent call to action at the Antimicrobial Resistance Summit 2011. Med J Aust. 2011;194(6):281-3.

18. Shao-Kang Z, Sheng-Lan T, You-De G, Bloom G. Drug prescribing in rural health facilities in China: implications for service quality and cost. Trop Doct. 1998;28(1):42-8

19. Segade BX. Impact of various objectives related to the rational use of medication in a primary care area. Aten Primaria. 2000;25(4):236-41.

20. Castán CS, García LF, Martínez GJ, Sierra MM, Solano BV, Peral CA. Minimizing the costs of prescription of anti-infective drugs in two areas of primary health care. Rev Esp Salud Publica. 1997;72(1):33-42.

21. Beringer PM, Wong-Beringer A, Rho JP. Economic aspects of antibacterial adverse effects. Pharmacoeconomics. 1998;13(1 Pt 1):35-49.

22. World Health Organization. How to investigate antimicrobial use in hospitals: selected indicators. 2012. http://apps.who.int/medicinedocs/ documents/s21031en/s21031en.pdf. Accessed 29 Oct 2015

23. Okeke IN, Laxminarayan R, Bhutta ZA, Duse AG, Jenkins P, O'Brien TF, et al. Antimicrobial resistance in developing countries. Part I: recent trends and current status. Lancet Infect Dis. 2005;5(8):481-93. doi:10.1016/S1473-3099(05)70189-4.

24. Howard DH, Scott 2nd RD. The economic burden of drug resistance. Clin Infect Dis. 2005:41 Suppl 4(Supplement 4):S283-286. doi:10.1086/430792.

25. Atif M, Sarwar MR, Azeem M, Umer D, Rauf A, Rasool A, et al. Assessment of WHO/INRUD core drug use indicators in two tertiary care hospitals of Bahawalpur, Punjab, Pakistan. J Pharm Policy Pract. 2016;9(1):27.

26. Hafeez A, Kiani AG, ud Din S, Muhammad W, Butt K, Shah Z, et al. Prescription and dispensing practices in public sector health facilities in Pakistan: survey report. J Pak Med Assoc. 2004;54(4):187-91.

27. Atif M, Azeem M, Sarwar MR, Shahid S, Javaid S, Ikram H, et al. WHO/INRUD prescribing indicators and prescribing trends of antibiotics in the Accident and Emergency Department of Bahawal Victoria Hospital, Pakistan. Springerplus. 2016;5(1):1928. doi:10.1186/s40064-016-3615-1.
28. Atif M, Sarwar MR, Azeem M, Naz M, Amir S, Nazir K. Assessment of core drug use indicators using WHO/INRUD methodology at primary healthcare centers in Bahawalpur, Pakistan. BMC Health Serv Res. 2016;16(1):684. doi:10.1186/s12913-016-1932-2.

29. Alliance for the Prudent Use of Antibiotics (APUA). Pakistan Chapter-Status of antibiotic resistance. 2014. http://emerald.tufts.edu/med/apua/intl_ chapters/pakistan.shtml. Accessed 21 Aug 2016

30. Finch RG, Metlay JP, Davey PG, Baker L. Educational interventions to improve antibiotic use in the community: report from the International Forum on Antibiotic Resistance (IFAR) colloquium, 2002. Lancet Infect Dis. 2004:4(1):44-53.

31. WHO Collaborating Centre for Drug Statistics Methodology. ATC/DDD Index 2017. 2017. https://www.whocc.no/atc ddd index/. Accessed 19 Mar 2017

32. World Health Organization. How to investigate drug use in health facilities: selected drug use indicators. 1993. http://apps.who.int/medicinedocs/en/d/ Js2289e/. Accessed 14 Nov 2015

33. Akl OA, El Mahalli AA, Elkahky AA, Salem AM. WHO/INRUD drug use indicators at primary healthcare centers in Alexandria. Egypt J Taibah Univ Med Sci. 2014;9(1):54-64.

34. Woldu MA, Suleman S, Workneh N, Berhane H. Retrospective study of the pattern of antibiotic use in Hawassa University referral hospital pediatric ward, Southern Ethiopia. J Appl Pharm Sci. 2013;3(2):93.

35. Green T, Omari M, Siddiqui AZ, Anwari J, Noorzaee A. Afghanistan medicine use study: a survey of 28 health facilities in 5 provinces. 2010. http://pdf. usaid.gov/pdf_docs/Pnadu426.pdf. Accessed 26 Mar 2017.

36. Palikhe N. Prescribing pattern of antibiotics in pediatric hospital of Kathmandu valley. Kathmandu Univ Med J. 2004;2(1):6-12.

37. Aswapokee N, Vaithayapichet S, Heller RF. Pattern of antibiotic use in medical wards of a university hospital, Bangkok, Thailand. Rev Infect Dis 1990:12(1):136-41.

38. Guyon AB, Barman A, Ahmed J, Ahmed A, Alam M. A baseline survey on use of drugs at the primary health care level in Bangladesh. Bull World Health Organ. 1994;72(2):265-71.

39. Massele AY, Nsimba SE, Rimoy G. Prescribing habits in church-owned primary health care facilities in Dar Es Salaam and other Tanzanian coast regions. East Afr Med J. 2001;78(10):510-4.

40. Holloway KA, Henry D. WHO essential medicines policies and use in developing and transitional countries: An analysis of reported policy implementation and medicines use surveys. PLoS Med. 2014;11(9):e1001724.

41. World Health Organization. Promoting rational use of medicines: core components - WHO policy perspectives on medicines. 2002. http://apps who.int/medicinedocs/en/d/Jh3011e/. Accessed 18 Oct 2015

42. Akande T, Ologe M, Medubi G. Antibiotic prescription pattern and cost at University of Ilorin teaching hospital, Ilorin, Nigeria. Int J Trop Med. 2009;4(2):50-4.

43. Khan FA, Singh VK, Sharma S, Singh P. A prospective study on the antimicrobial usage in the medicine department of a tertiary care teaching hospital. J Clin Diagn Res. 2013;7(7):1343-6. doi:10.7860/JCDR/2013/6265.3125.

44. File Jr TM. New guidelines for antimicrobial prophylaxis in surgery. Infect Dis Clin Pract. 2013:21(3):185-6.

45. Bratzler DW, Dellinger EP, Olsen KM, Perl TM, Auwaerter PG, Bolon MK, et al. Clinical practice guidelines for antimicrobial prophylaxis in surgery. Am J Health Syst Pharm. 2013;70(3):195-283.

46. Mandell LA, Wunderink RG, Anzueto A, Bartlett JG, Campbell GD, Dean NC, et al. Infectious Diseases Society of America/American Thoracic Society consensus guidelines on the management of community-acquired pneumonia in adults. Clin Infect Dis. 2007:44 Suppl 2:S27-72. doi:10.1086/511159.

47. Hu S, Liu X, Peng Y. Assessment of antibiotic prescription in hospitalised patients at a Chinese university hospital. J Infect. 2003;46(3):161-3.

48. Jimoh AO, Etuk EU, Sani Z, Shuaibu HA. The pattern of antibiotic use in a family medicine department of a tertiary hospital in Sokoto, North Western Nigeria. J Clin Diagn Res. 2011;5(3):566-9.

49. World Health Organization. The world health report 1996: fighting disease; fostering development. 1996. http://www.who.int/whr/1996/en/. Accessed 14 Nov 2015

50. World Health Organization. Interventions and strategies to improve the use of antimicrobials in developing countries. Drug Management Program. 2001. http://www.who.int/csr/resources/publications/drugresist/WHO_CDS_ CSR DRS 2001 9/en/. Accessed 14 Nov 2015

51. Al-Niemat SI, Aljbouri TM, Goussous LS, Efaishat RA, Salah RK. Antibiotic prescribing patterns in outpatient emergency clinics at Queen Rania Al Abdullah II children's hospital, Jordan, 2013. Oman Med J. 2014;29(4):250-4. 
52. Rao GG, Patel M. Urinary tract infection in hospitalized elderly patients in the United Kingdom: the importance of making an accurate diagnosis in the post broad-spectrum antibiotic era. J Antimicrob Chemother. 2009;63(1):5-6.

53. Nicolle LE. Committee* ACG. Complicated urinary tract infection in adults. Can J Infect Dis Med Microbiol. 2005;16(6):349-60.

54. Woodford HJ, George J. Diagnosis and management of urinary infections in older people. Clin Med (Lond). 2011;11(1):80-3.

55. Ejim L, Farha MA, Falconer SB, Wildenhain J, Coombes BK, Tyers M, et al. Combinations of antibiotics and nonantibiotic drugs enhance antimicrobial efficacy. Nat Chem Biol. 2011;7(6):348-50. doi:10.1038/nchembio.559.

56. Rybak MJ, McGrath BJ. Combination antimicrobial therapy for bacterial infections. Guidelines for the clinician. Drugs. 1996;52(3):390-405.

57. Cremieux AC, Carbon C. Pharmacokinetic and pharmacodynamic requirements for antibiotic therapy of experimental endocarditis. Antimicrob Agents Chemother. 1992;36(10):2069-74

58. Cottarel G, Wierzbowski J. Combination drugs, an emerging option for antibacterial therapy. Trends Biotechnol. 2007;25(12):547-55. doi:10.1016/j.tibtech.2007.09.004.

59. Hegreness M, Shoresh N, Damian D, Hartl D, Kishony R. Accelerated evolution of resistance in multidrug environments. Proc Natl Acad Sci U S A 2008;105(37):13977-81. doi:10.1073/pnas.0805965105.

60. Michel JB, Yeh PJ, Chait R, Moellering Jr RC, Kishony R. Drug interactions modulate the potential for evolution of resistance. Proc Natl Acad Sci U S A. 2008;105(39):14918-23. doi:10.1073/pnas.0800944105.

61. Pena-Miller R, Laehnemann D, Jansen G, Fuentes-Hernandez A, Rosenstiel P, Schulenburg $\mathrm{H}$, et al. When the most potent combination of antibiotics selects for the greatest bacterial load: the smile-frown transition. PLoS Biol. 2013:11(4):e1001540.

\section{Submit your next manuscript to BioMed Central and we will help you at every step:}

- We accept pre-submission inquiries

- Our selector tool helps you to find the most relevant journal

- We provide round the clock customer support

- Convenient online submission

- Thorough peer review

- Inclusion in PubMed and all major indexing services

- Maximum visibility for your research

Submit your manuscript at www.biomedcentral.com/submit 